\title{
$\operatorname{arCOS} D E S I G N$
}

\section{Laboratório de Design e Antropologia: preâmbulos teóricos e práticos}

Zoy Anastassakis, PhD. (UERJ, Brasil)

zoy@esdi.uerj.br

Escola Superior de Desenho Industrial - PPD ESDI

Rua Evaristo da Veiga, 95, Lapa , Rio de Janeiro, RJ, CEP: 20031-040 


\title{
Laboratório de Design e Antropologia: preâmbulos teóricos e práticos
}

Resumo: O artigo relata uma experiência realizada na ESDI/UERJ. Buscando explorar possíveis articulações entre extensão, pesquisa e ensino, dialogamos com os trabalhos mais recentes do antropólogo britânico Tim Ingold. Com isso, intentamos experimentar, na prática, um exercício da interdisciplinaridade entre design e antropologia. Neste artigo, compõe-se um relato preliminar das primeiras experimentações realizadas entre 2012 e 2013, sobretudo no que concerne as relações entre antropologia e interdisciplinaridade, prática e ensino de pesquisa, em um trânsito dialógico entre design e antropologia.

Palavras-chave: design, antropologia, interdisciplinaridade

\section{Design and Anthropology Lab: theoretical and practical preambles}

\begin{abstract}
The paper reports an experiment conducted at ESDI/UERJ. Intending to explore possible links between extension, research and teaching, we dialogue with the more recent work of Tim Ingold. Therefore, we attempted to experience, in practice, an interdisciplinary exercise between design and anthropology. In this paper, we compose a preliminary report of the first experimentations realized between 2012 and 2013, especially those regarding the relationship between anthropology and interdisciplinary, research practice and teaching, in a dialogical movement between design and anthropology.
\end{abstract}

Key words: design, anthropology, interdisciplinarity 


\section{Introdução}

Este artigo trata de uma série de experiências iniciadas em 2012, na Escola Superior de Desenho Industrial da Universidade do Estado do Rio de Janeiro (ESDI/UERJ): primeiramente, no âmbito de um projeto de extensão, com desdobramentos que culminaram, em 2013, na criação do Laboratório de Design e Antropologia (LaDA), projeto de pesquisa constituído a partir de uma parceria entre ESDI e IFCS/UFRJ, com apoio da FAPERJ. Buscando explorar algumas possíveis articulações entre ensino, pesquisa e extensão, os dois projetos se articulam também a propostas pedagógicas, nos níveis de graduação e pós-graduação, através das disciplinas ministradas a partir de 2012 pelas professoras-pesquisadoras Zoy Anastassakis (coordenadora de ambos os projetos) e Barbara Szaniecki (pesquisadora associada).

Neste artigo, exploramos, em termos teóricos e práticos, o que fundamenta a criação do Laboratório de Design e Antropologia. Por isso, nos concentramos nas atividades realizadas entre o segundo semestre de 2012 e o primeiro semestre de 2013, seja em sala de aula, na disciplina Meios e Métodos de Representação do Projeto, ministrada no terceiro ano da graduação, seja no âmbito do projeto de extensão, denominado Observatório Etnográfico de Design e Inovação Social no Rio de Janeiro.

Organizado a partir de algumas propostas formuladas por Gunn (2009, 2012) e Ingold $(2011,2013)$ no sentido de uma experimentação interdisciplinar entre arquitetura, arte, design e antropologia, o projeto de extensão tinha por objetivo primordial experimentar, na prática, um exercício da interdisciplinaridade entre design e antropologia, interface disciplinar em expansão, haja vista a existência, nos dias de hoje, de dois programas de mestrado intitulados 'design anthropology' (Anastassakis 2012): um deles oferecido pelo departamento de design da Swinburne University of Technology, Austrália, o outro pelo departamento de antropologia da Universidade de Aberdeen, Escócia.

Além de Aberdeen e Swinburne, é possível citar pelo menos mais três programas de mestrado que, embora com diferentes denominações, organizam-se em torno da categoria 'design anthropology': 'design ethnography', no Duncan of Jordanstone College of Art \& Design, da Universidade de Dundee, na Escócia; "Culture, Materials \& Design", no departamento de antropologia da University College London, Inglaterra; e "Information Technology - Product Design", no SPIRE (Sondenborg Participatory Research Centre), do Mads Clausen Institute, Faculdade de Engenharia da University of Southern Denmark, em Sondenborg, Dinamarca.

Não é por acaso que Wendy Gunn e Tim Ingold estejam vinculados a instituições onde surgiram dois desses programas: o departamento de 
antropologia da Universidade de Aberdeen, fundado por Ingold, e o SPIRE, da University of Southern Denmark, onde Gunn é professora associada. Além disso, deve-se mencionar que o mestrado em 'design anthropology' de Aberdeen foi elaborado a partir de um convênio entre as universidades escocesa e dinamarquesa, embora nem Gunn nem Ingold estejam, hoje, diretamente envolvidos com sua condução.

Levada a cabo na ESDI/UERJ na forma de projeto de extensão universitária, a experiência em torno do Observatório Etnográfico de Design e Inovação Social no Rio de Janeiro foi delineada através de experimentos de conjugação entre pesquisa etnográfica e exercícios imaginativos e prospectivos organizados em torno da região compreendida entre Largo da Lapa, Passeio Público, Cinelândia e Largo da Carioca, zona central da cidade do Rio de Janeiro. Tomando essa região por terreno e tema de trabalho, buscou-se experimentar, a partir da prática, uma abordagem interdisciplinar entre o design e a antropologia, inspirada pelas formulações de Ingold $(2000,2011)$ sobre as relações entre lugares, movimento e conhecimento, descrição e imaginação. Trata-se, assim, de um exercício de experimentação interdisciplinar que toma o lugar, entendido aqui segundo as formulações desse antropólogo britânico, como campo de pesquisa e ação.

\section{Explorando novos sentidos para a interdisciplinaridade}

Antes de avançar com a narrativa sobre a experiência do Observatório, é importante qualificar o modo como se percebe, aqui, a questão da interdisciplinaridade, e os novos sentidos com que ela pode ser investida na contemporaneidade, mote para a formulação do projeto em questão. Antes de mais nada, é preciso ressaltar, como afirma Otávio Velho, que as ciências vem navegando há algum tempo nas águas de um processo de interdisciplinarização (2010, 218) que passa pela interdefinição dos sistemas, e não mais pela sua constituição como essências (idem). Em meio a tal movimento, comentado por Velho, os cientistas sociais terminam, por vezes, marginalizados, limitados que estão ao seu antropocentrismo (idem, 220).

Afinal, e de forma paradoxal, para além das ciências sociais, as demais organizações científicas vem operando, muitas das vezes, como demonstra a etnografia de Marilyn Strathern (2005) citada por Velho, "articulando diversas comunidades acadêmicas e não-acadêmicas e fazendo com que a noção de conhecimento incorpore a sua validação por uma opinião que não é mais apenas a dos pares - o que não é de pequena monta” (2010, 219).

Considerando tal quadro, Velho sugere "quatro atitudes possíveis para os cientistas sociais diante dessas novas ciências e dessa nova 
interdisciplinaridade" (idem, 224). A partir delas, propõe que se opte por aquelas que contribuam de forma mais substantiva para a substituição de "binômios que ainda supõem uma subalternidade - como o de controle e diferença - pelo reconhecimento de outros mundos possíveis" (idem).

A limitação ao antropocentrismo que, segundo Velho, é um dos fatores que tem levado os cientistas sociais a um lugar marginal em meio aos processos de interdisciplinarização experimentados por outros ramos das ciências, é, também para Ingold, um impasse. Em sua perspectiva, nós, antropólogos, devemos superar a divisão canonizada entre os dois mundos da natureza e da sociedade e também aquela que separa em categorias distintas seres humanos e não-humanos, deslocando "o foco dos sujeitos e de suas relações para a vida e seus fluxos e linhas que ganham forma nos materiais que nos constituem a todos que fazemos parte do ambiente-mundo" (CARVALHo; STEIL 2012, 09), ou seja, redirecionando a antropologia de volta à vida, tout court.

Uma antropologia entendida como modo inquisitivo de estar no mundo, em que o compromisso com a observação e a descrição esteja conjugado a um engajamento propositivo no sentido de uma transformação desse mesmo mundo, algo mais aproximado da liberdade criativa que é convencionalmente delegada às disciplinas como a arte, a arquitetura e o design. Assim, na busca de reintroduzir a antropologia de volta às questões concretas da vida, Ingold sugere que desloquemos seu centro de gravidade no sentido de uma aproximação com outros campos do saber, tais como os supra-citados. É a partir desse lugar que ele anuncia a possibilidade de surgimento de uma nova disciplina, esperando para ser definida e nomeada (2011, xi).

Contudo, é importante notar que não se trata aqui, como pondera Gunn (2009), de uma abordagem que toma por objeto de análise antropológica o design, a arte e/ou a arquitetura, mas, sim, de um esforço para revelar a sinergia entre a antropologia e essas disciplinas, uma sinergia que reside não apenas nos produtos que delas resultam, mas sobretudo nos modos de produção do conhecimento, no contexto de um diálogo interdisciplinar em andamento.

Nesse sentido, Ingold propõe que se experimente desenvolver "uma antropologia por meio do design" (2013), onde design é o processo de pesquisa, em que pesquisadores se conjugam às pessoas, em seus desejos e aspirações, a fim de enriquecer tais vidas, tornando-as mais sustentáveis. Para isso, uma tal antropologia, operacionalizada através de processos de design, deve ser, sobretudo, experimental e improvisatória. Uma antropologia comprometida com um projeto sustentável (INGOLD 2013, 03).

Afinal para este autor, tanto a arquitetura, quanto a arte, o design e a antropologia observam, descrevem e propõem. Assim, a compreensão matizada dos diferentes modos com que a vida é experimentada, mais facilmente 
associável à uma abordagem antropológica, é também o que ancora as proposições criativas do design, da arte e da arquitetura. Por outro lado, reciprocamente, não há razão para que a antropologia se restrinja a somente observar e descrever as condições e possibilidades da vida no mundo, furtando-se a um comprometimento mais engajado com a sua transformação, perspectiva mais tradicionalmente associada àquelas disciplinas, e demais áreas do saber ligadas de forma mais direta à criatividade.

Desse modo, arquitetura, arte e design, assim como a antropologia, são tomadas como formas de engajamento exploratório e especializado que moldam nossos ambientes e os modos como eles são percebidos (GUNN 2009, 01). Trata-se, então, de uma proposta que enfatiza a prática da interdisciplinaridade, ou seja, um modo distinto de fazer antropologia junto a outras disciplinas, mais do que uma antropologia delas ou sobre elas (idem), buscando encontrar lugares compartilhados de compreensão através da prática interdisciplinar (idem, 03), lugares esses que transcendam os limites dos modos específicos de trabalho e produção de conhecimento disciplinarmente organizados.

Essa proposta de restituição da antropologia à vida, ancorada na ideia de um engajamento comprometido com a transformação do mundo e das formas de vida, e estruturada a partir do exercício prático da interdisciplinaridade, implica também em propostas educacionais (velHo 2012, 229). Assim, a teoria do conhecimento que se funda sobre o engajamento (CARVALHO; STEIL 2012, 08), formulada por Ingold, se desenrola, forçosamente, em uma proposta para a educação da atenção (idem) que se pretende realizar a partir da conjugação entre ensino e pesquisa.

Segundo tal perspectiva, devemos romper com a distinção entre esses dois domínios, que termina por isolar os estudantes de nossas práticas investigativas, retirando deles a possibilidade de um envolvimento compartilhado em pesquisas de campo, seja conosco, professores, ou com outros colegas. Desse modo, transformamos a sala de aula em um espaço de discussão sobre antropologia, e não em um lugar onde se faz antropologia, de fato. Para Ingold, entretanto, deveríamos passar mais tempo em campo com os alunos, desenvolvendo atividades concretas, do que na sala de aula, discutindo sobre as coisas.

A partir dessa formulação, a noção de engajamento, vinculada à uma proposta de redirecionamento da prática antropológica, expande-se concomitantemente para a educação em antropologia, impossível de ser dissociada da prática da disciplina. Assim, Ingold reinsere no ambiente-mundo a ciência social e, por conseqüência, os cientistas sociais e seus alunos, ambos tomados como habitantes do mundo e que, por isso, não escapam da obrigatoriedade de participação engajada nos fluxos da vida. Uma tal antropologia é sobretudo, 
então, o exercício compartilhado de um modo inquisitivo de habitar o mundo, em que diversos praticantes, todos eles habitantes do mundo, interagem.

Proposta que se aproxima da noção de 'design studio', formulada por George E. Marcus (2008) em sua defesa pela renovação da prática e do ensino de pesquisa em antropologia. Discutindo as possibilidades de novas pedagogias para o ensino de etnografia, Marcus propõe que a tomemos por uma prática projetual. Assim, praticar etnografia como em um estúdio de design é, para Marcus, um modo de desenvolver idéias alternativas sobre os métodos de pesquisa, de forma mais compartilhada e crítica. Ou seja, trata-se de criar espaços institucionais para o ensino de uma antropologia informada pelo conceito de projeto, ou design. Uma plataforma para a fusão entre pesquisa e ensino.

Contudo, deve-se salientar que investir em uma proposta como esta dentro de uma escola de design não significa que se esteja pretendendo, ali, formar antropólogos, nem tampouco instrumentar estudantes de design com 'métodos' e 'ferramentas' retirados da antropologia, que possam ser aplicados às suas práticas de design. Implica, outrossim, em uma aposta na possibilidade de conformação de uma nova forma de fazer design e antropologia, de forma simultânea, o que se pretende experimentar através da conjugação de seus modos de produção de conhecimento em torno de um compromisso dialógico com as questões que nos cercam a todos, habitantes de um mesmo mundo. Destarte, deve ficar claro que o que está em jogo aqui não é nem uma antropologia do design, nem um design antropológico, mas, sim, o exercício de uma experimentação interdisciplinar que busca operar a partir do diálogo entre as duas disciplinas.

Um tal exercício da interdisciplinaridade - onde a prática antropológica é percebida como um processo de comunicação que opera de forma plural, não clivada pelas limitações disciplinares tradicionais - é entendido, aqui, também, como um dos pressupostos do que o antropólogo João Pacheco de Oliveira (2009) define como um novo exercício da antropologia, discussão também levantada por Marcus e Rabinow, no livro "Designs for an anthropology of the contemporary" (2008), acima mencionado.

Segundo Oliveira (2009), o cenário da globalização vem pressionando os antropólogos a se lançar em busca de novas estratégias de investigação que possam favorecer o desenvolvimento da pesquisa em contextos contemporâneos, bastante distintos daqueles onde se formulara algumas das verdades operacionais hoje cristalizadas pela disciplina.

Em meio a essa discussão, Oliveira propõe que se perceba o surgimento de novas práticas de investigação de forma positiva, buscando acompanhá-las, observando seus resultados, e tomando, assim, consciência sobre os campos de possibilidade por elas abertos, bem como os seus limites. Uma postura 
contrária, de caráter normativo e repressor, poderia constituir um verdadeiro obstáculo para a atividade científica, modus operandi através do qual também a antropologia opera. Nesses termos, buscar escapar da pressão homogeneizadora de uma normatividade que se ancora em momentos passados seria o primeiro passo para se assumir a prática antropológica de modo plural, e para aceitar, de forma consciente, toda sua dimensão ética e política, o que, mais uma vez, se aproxima das propostas de Marcus (2008).

Nessas formulações em defesa de novos padrões para o exercício antropológico, mais uma vez, assim como na perspectiva de Ingold, já comentada, tem destaque a questão do engajamento do pesquisador com as preocupações e demandas das coletividades com as quais se desenvolve a pesquisa. Nesse contexto, está em jogo uma ruptura com algumas das verdades operacionais da disciplina, entre elas aquela que postula a necessidade de neutralidade daquele que realiza a pesquisa face às demandas dos grupos com os quais se trabalha, o que, por conseqüência, implica na assunção do caráter situacional e dialógico, portanto político, do trabalho etnográfico e antropológico.

Segundo a perspectiva de Oliveira, o melhor modo de fazer avançar o conhecimento, dado esse quadro de iminência de novas modalidades para o exercício antropológico, é colocar em discussão, de forma rigorosa e consciente, as condições através das quais se realizam os trabalhos de campo. Se eles avançam, buscando incorporar as novas potencialidades da conjuntura política e científica, devem resguardar, sobretudo, dois valores centrais para a disciplina antropológica: o rigor crítico na produção dos dados e o respeito pelas pessoas com que se trabalha. Este artigo faz parte de um tal esforço, a saber, aquele de compartilhar e, assim, colocar à prova, as experimentações realizadas por nós, explicitando as condições em que se realiza o exercício interdisciplinar que coloca em diálogo design e antropologia.

\section{Em algum lugar do Rio de Janeiro, na região central da cidade}

Se alguém procura localizar a Escola Superior de Desenho Industrial (ESDI/ UERJ) através da ferramenta de busca do Google Maps não encontra resposta. Mas se o endereço da escola for digitado, a ferramenta conduz aquele que busca à zona central da cidade do Rio de Janeiro. O primeiro recorte na imagem, selecionado pelo Google, se estende, mais ou menos, e a depender da tela do computador onde se faça a busca, da Praça da Cruz Vermelha, à esquerda, do bairro de Fátima à Praça Paris, na margem inferior, passando pela enseada da Glória no canto inferior direito, pelo Museu de Arte Moderna, no final do Aterro do Flamengo, na margem direita, e, por fim, pelos Largos da Misericórdia e da Carioca e pela Praça da República, na margem superior. No momento em que surge a imagem, já está sinalizado, no centro da tela, um 
ponto vermelho que marca a Rua Evaristo da Veiga, à altura do Largo da Lapa, onde ela encontra a Av. República do Paraguai.

Fazendo essa busca com os alunos em sala de aula, optamos pela visualização via satélite. Observando a imagem, percebemos que a quadra contígua à escola, compreendida entre as Rua Evaristo da Veiga, Senador Dantas, do Passeio e das Marrecas ainda aparecia repleta de edifícios, o que indica que a foto foi tirada já há algum tempo, pois tal quadra se encontra, hoje, em um estado completamente diferente, na medida em que todo o seu miolo foi demolido, dando lugar a um grande canteiro de obras.

Quem percorre o Rio de Janeiro, seja a pé, de carro, bicicleta, ou em algum tipo de transporte público, como ônibus, vans, trens e metrô, passa não apenas por esse canteiro de obras, mas por inúmeros outros, em todas as regiões da cidade, zonas norte, oeste, sul e também no centro. Grande parte dessas obras está diretamente ligada com a preparação de dois importantes eventos esportivos, que terão a cidade como sede: a Copa do Mundo de Futebol, em 2014, e os Jogos Olímpicos, em 2016.

Se a iminência desses eventos criou para a cidade uma agenda complexa de obras de infra-estrutura, exigidas pela FIFA e pelo Comitê Olímpico com a justificativa de se criar condições para a realização das competições e de tudo o que as envolve, provocou também a aceleração de um processo de 'transformação' do ambiente urbano, seja em escala regional e a partir de iniciativas públicas, como nos casos da ampliação do metrô, da 'pacificação' das favelas e do projeto de 'revitalização' da região portuária; seja em escala local e através de iniciativas públicas e/ou privadas, passando pela demolição de edifícios antigos para a construção de novos, se expandindo, ainda, até uma hipervalorização dos imóveis, o que, por conseqüência, vem gerando um violento processo de especulação imobiliária.

Sendo 2012 ano de eleições municipais, todo esse processo de 'transformação' da cidade se tornou um dos temas centrais do debate público. Afinal, o que parecia estar em jogo, naquele momento, era não somente a preparação dos eventos esportivos, mas, sobretudo, uma série de reconfigurações do ambiente urbano carioca postas em movimento a partir do que a preparação dos eventos parecia exigir. Esse processo vinha sendo agenciado por diversas sortes de atores, em distintas instâncias e sob as mais variadas justificativas. Além de ocupar as manchetes dos jornais, e de inflamar os debates entre candidatos à prefeitura, era também assunto de todos os dias, em quase todos os lugares. 


\section{Um observatório entre o design e a antropologia}

O Observatório Etnográfico de Design e Inovação Social no Rio de Janeiro surge naquele contexto, a partir de uma percepção sobre o momento da cidade, que demandava, também na universidade, um lugar onde a discussão pudesse se desdobrar em observações atentas que derivassem, por sua vez, em novos debates e propostas alternativas que forjassem, então, renovadas instâncias de diálogo, entre a cidade e a universidade.

Em um curso de design, tais questões ganhavam ainda outras dimensões, na medida em que havia, naquele momento, por parte da gestão Eduardo Paes, prefeito reeleito no processo eleitoral de 2012, um crescente interesse pela interlocução com a comunidade de design local, necessariamente envolvida em diversos dos projetos sendo desenvolvidos na cidade, em torno da agenda acima descrita. A experimentação em torno do Observatório buscava conjugar, então, uma série de interesses de pesquisa, que, através de um projeto de extensão, poderiam, enfim, se desdobrar tanto para o ensino quanto para um diálogo efetivo com as questões postas pela vida social, para além das barreiras disciplinares, tal como as distingue a academia.

O trabalho teve início com uma indagação a respeito do próprio lugar onde nós nos reuníamos, como freqüentadores de um mesmo ambiente de formação para atuação profissional em design, a saber, a ESDI, situada na Lapa, região central da cidade do Rio de Janeiro. A partir daí, realizamos uma série de exercícios entre a observação e a descrição do que se percebia em campo e a discussão e a imaginação de outros modos de ser para esse lugar e a região na qual ele se insere. Esses exercícios envolveram trabalho de campo, análise estratégica e prospecção de cenários futuros, produção de textos, diagramas e peças gráficas, um workshop com participantes externos, e duas exposições, montadas, a primeira, em uma feira de extensão na UERJ, e a segunda, após o workshop, nos muros da própria ESDI, em sua face para a Rua Evaristo da Veiga.

Além disso, tivemos oportunidade de apresentar e discutir o trabalho em andamento na mesa-redonda "Desincubando a criatividade na metrópole", organizada pela Universidade Nômade, na Casa de Rui Barbosa, e em um 'showcase' da Rede Desis (Design de Serviços e Inovação Social), coordenada pelo Prof. Ezio Manzini, do Politécnico de Milão, com organização local pela Prof. Carla Cipolla, da COPPE/UfRJ.

Ao longo dessa primeira etapa de trabalho, nós, da equipe do Observatório, fomos percebendo que todas as nossas atividades eram alimentadas, mais do que tudo, pelas distintas instâncias de diálogo que iam sendo provocadas através de cada uma delas. Assim, passamos a entender que estávamos envolvidos em um processo que se articulava entre a criação de dispositivos que 
provocassem novas possibilidades de debate, entre nós, dentro da universidade, e com os próprios lugares, fora dela.

Trazer à tona algumas questões, tornando-as visíveis e provocando oportunidades para sua discussão, o que, por si, contribuía para a formulação de novas questões, que se buscava, sob novas formas, tangibilizar na forma de novas provocações que se tornassem visíveis, forjando novas discussões, em outros lugares, e, assim, sucessivamente. Nesse sentido, logo nos percebemos envolvidos em um processo que alternava observação, descrição, discussão e imaginação de lugares, em um exercício investigativo e propositivo sobre os lugares, observados e também imaginados, mas, que sobretudo, se realizava em um lugar, e em torno da região onde esse lugar se encontra.

Levando em consideração tais formulações, o que significaria então, para nós, acostumados a freqüentar esses lugares em torno da escola em nossas atividades cotidianas, passar a percorrê-los em trabalho de campo? Quando se iniciaria e quando se terminaria, então, o trabalho? Quando se estaria em campo ou fora dele, dentro ou fora da escola? Era exatamente um tal estado de confusão que eu buscava cultivar entre os alunos e em mim mesma, acreditando que assim estaríamos exercitando novas formas de atenção para os lugares onde vivemos nossas vidas, em meio a nossas atividades habituais. Nos engajar na busca de novas formas de percepção dos lugares onde vivemos, a fim de fazer deles, e sobretudo de nossos percursos ao longo deles e entre eles, não apenas os espaços por onde passamos, indo de um lugar a outro, mas, sim, um campo de relações, a partir de onde podemos extrair questões que alimentem o que entendemos ser o nosso 'trabalho'.

Para dar início a esse trabalho, pedimos que os alunos representassem graficamente, e de memória, o ambiente da escola e seus entornos. O suporte para essa representação deveria ser um espaço da própria escola, não previamente designado para tal fim. Observando juntos os desenhos, percebemos o que cada um de nós lembrava, que memórias eram suscitadas, que histórias afloravam. Nessa ocasião, além dos desenhos, observamos juntos um conjunto de imagens que representavam a ESDI em uma série de situações distintas, exercício que tinha por fim provocar nos alunos uma sensibilidade para o que constituía aquele ambiente como um lugar investido de diversos sentidos, histórias, memórias, nem todos necessariamente partilhados por nós ou perceptíveis para alguém que ali entrasse pela primeira vez.

Em seguida, propusemos que tentássemos sobrepor os desenhos àquela visão de satélite disponibilizada pelo Google Maps, buscando encontrar pelo menos algum ponto de conexão entre as duas camadas sobrepostas em transparência. Observando, então, o recorte proposto pela ferramenta de busca, percebemos que aquela seção, acima descrita, dava conta de uma região 
suficientemente grande para apresentar variadas possibilidades para o trabalho de campo, sendo, ao mesmo tempo, de uma extensão que é facilmente percorrível a pé, o que viabilizaria nossas idas e retornos ao campo, a partir da escola.

Nesse momento, desenvolvíamos as mesmas atividades entre os alunos, em sala de aula, e com a equipe de projeto, em nossos encontros semanais. A partir do exercício com os desenhos e o mapa do Google, decidimos dar início a um trabalho de campo que se realizaria na forma de um mapeamento (Ingold 2000, 219-242), o que não significava, naquele momento, que estivéssemos empenhados em ir a campo buscando coletar dados para a realização de algum mapa, em um momento futuro. Mapear a região do entorno da escola consistiria, tão somente, em realizar percursos (idem) que nos fariam passar de um lugar (idem, 219; 2011, 145-155) a outro, atividade ambientalmente situada que, nos colocando em movimento, tinha por objetivo provocar o desvelamento de um campo de relações e histórias que é, segundo Ingold, o que constitui propriamente um lugar.

Partimos para o mapeamento nos dividindo em grupos, cada um deles escolhendo um lugar a partir de onde daria início a uma série de percursos de observação. A cada encontro em sala de aula, compartilhávamos o que havia sido observado em campo e comentávamos os desenhos, as anotações, fotografias e narrativas produzidas. Enquanto íamos e vínhamos do campo, demos início a um processo de análise inspirado em procedimentos oriundos do design estratégico, sobretudo em sua matriz italiana (Politécnico de Milão), alguns deles atualizados por pesquisadores da Escola de Design da Unisinos (RS), como Paulo Reyes (2010). Buscávamos então extrair questões-chave que alimentassem um processo de desenvolvimento de visões de cenários alternativos para a vida nos lugares observados.

Esses eram, sobretudo, exercícios de imaginação que buscavam projetar outras visões sobre esses lugares, e a partir das questões aí percebidas, configurar dispositivos de comunicação que forjassem novas discussões, em campo. Nesse ponto, experimentamos vários meios e métodos de representação visual, optando por aqueles que facilitassem a comunicação de nossas visões imaginadas, visões essas que desejávamos levar a campo para que os transeuntes e demais habitantes da região pudessem nelas interferir, criando, assim, mais discussão e levantando, novamente, outras questões.

Trabalhar em campo, trazendo dele e a ele devolvendo renovadas questões, foi, então, o modo através do qual ensaiamos dar início à experimentação de conjugação entre ensino, pesquisa e extensão, no âmbito de uma proposição interdisciplinar entre o design e a antropologia, que tomava como lugar de trabalho a região em torno da qual nós nos formamos enquanto um grupo envolvido no exercício da formação para atuação profissional em design. 
Ao longo do primeiro período de trabalho, realizado durante o segundo semestre de 2012, fomos e retornamos a campo inúmeras vezes, trazendo observações e a ele retornando com provocações (LENSKJOLD 2011) que dessem margem a diálogos com os habitantes e os transeuntes, nos diversos lugares por onde passamos. Nesse processo, testamos diversas estratégias para fomentar um ambiente de provocação ao diálogo em campo, que fosse facilitado por peças gráficas desenvolvidas por nós. Entretanto, percebemos que, mais do que criar intervenções gráficas que instigassem os passantes sobre as questões que gostaríamos de debater, era preciso estar na rua, junto ao material que eventualmente daria suporte para que nos envolvêssemos em processos de comunicação.

Assim, entendemos que os prováveis desdobramentos futuros do projeto deveriam envolver pesquisa e experimentação sobre novas formas de estar em campo, onde os processos de observação, movimentação, descrição e imaginação estejam conjugados a serviço da criação de ambientes de engajamento dialógico entre nós e todos os demais habitantes com quem partilhamos os lugares, tais como esses, na região central do Rio de Janeiro.

\section{Considerações finais}

A partir das considerações feitas ao fim desse primeiro período de atividade, percebemos também a necessidade de se criar, em torno do projeto, um envolvimento mais diretamente relacionado com as pessoas que, como nós, vivem nesses lugares. Buscando explorar essa dimensão, estabelecemos uma parceria com a Agência de Redes para Juventude, ong que agencia projetos de jovens moradores de comunidades atingidas pelo programa das Unidades de Polícia Pacificadora (UPPs). A parceria tinha como foco central o desenvolvimento de elementos que facilitassem a comunicação do impacto que cada um dos projetos gerava em seu território, bem como das 'metodologias' utilizadas por ele para tal fim.

Durante um mês de trabalho, no período das férias de verão, início de 2013, montamos 18 duplas de projeto, formadas cada uma por um jovem líder de projeto na Agência e um estudante de design. Essas duplas trabalharam no sentido de mapear o impacto dos projetos, assim como de comunicar, de forma sintética e visual, os modos de atuação e o alcance dessa atuação no território. Como resultado, foram criadas identidades visuais para os projetos, bem como dois mapas: 1) metodológico e 2) de impacto no território. Esses mapas deviam servir para facilitar a comunicação dos jovens sobre seus projetos, viabilizando futuras parcerias.

A partir dessa parceria, desdobrou-se uma outra: junto à designer (pesquisadora da CAPES na ESDI/UERJ), Barbara Szaniecki, e à antropóloga Karina 
Kuschnir (professora e pesquisadora no Instituto de Filosofia e Ciências Sociais da Universidade Federal do Rio de Janeiro, IFCS/UfRJ) criamos o Laboratório de Design e Antropologia, que através de apoio da Fundação de Amparo à Pesquisa no Rio de Janeiro (FAPERJ), foi instalado na ESDI. Buscando conjugar nossas atividades de ensino, pesquisa e extensão no IFCS/UFrJ e na ESDI/UERJ, trabalhamos para criar um ambiente ampliado de experimentação e discussão critica sobre as interfaces possíveis entre design e antropologia.

\section{Referências bibliográficas}

ANASTASSAKIS, Z. Design and Anthropology: an interdisciplinary proposition. 4th International Forum of Design as a Process. Belo Horizonte: Universidade do Estado de Minas Gerais, 2012.

CARVALHO, I. M. C. de M.; STEIL, C. A. (Orgs.). Cultura, percepção e ambiente: diálogo com Tim Ingold. São Paulo: Editora Terceiro Nome, 2012.

GUNN, W. (Ed.). Fieldnotes and sketchbooks: challenging the boundaries between descriptions and processes of describing. Frankfurt am Main: Peter Lang GmbH, 2009.

GUNN, W.; DONOVAN, J. (Eds.). Design and Anthropology. Surrey and Burlington: Ashgate, 2012.

INGOLD, T. Knowing From the Inside: Anthropology, Art, Architecture and Design. Projeto de Pesquisa subsidiado pelo European Research Council, Aberdeen University, Escócia, 2013. Link: http://www.abdn.ac.uk/anthropology/postgrad/art-architecture-design.php

INGOLD, T. Being Alive: essays on movement, knowledge and description. London and New York: Routledge, 2011.

INGOLD, T. The Perception of the Environment: essays on livelihood, dwelling and skill. London and New York: Routledge, 2000.

LENSKJOLD, T. U. Accounts for a critical artefacts approach to design anthropology. Nordic Design Research Conference, Helsinki, 09p., 2011.

MARCUS, G. E.; RABINOW, P. Designs for an anthropology of the contemporary. Durham and London: Duke University Press, 2008. 
OLIVEIRA, J. P. de. Pluralizando tradições etnográficas. Cadernos do Leme, v. 1, n.1. Campina Grande, jan-jun, p. 02-27, 2009.

REYES, P. "Tudo o que não invento é falso": por uma epistemologia da imaginação criadora no design. Strategic Design Research Journal, 3(3), set-dez, p. 102-108, 2010.

REYES, P. Construção de cenários no design: o papel da imagem e do tempo. $\mathbf{9}^{\circ}$ Congresso Brasileiro de Pesquisa e Desenvolvimento em Design, São Paulo, 2010.

STRATHERN, M. Experiments in interdisciplinarity. Social Anthropology, 13(1), p. 75-90, 2005.

VELHO, O. Os novos sentidos da interdisciplinaridade. Mana, 16(1), p. 213226, 2010. 
Recebido em: 10/03/2013

Aceito em: 01/05/2013

\section{Como citar}

ANASTASSAKIS, Z. Laboratório de Design e Antropologia: preâmbulos teóricos e práticos. Arcos Design. Rio de Janeiro: PPD ESDI - UERJ. Volume 7 Número 1 Junho 2013. pp. 178-193. Disponível em: [http://www.e-publicacoes.uerj.br/index.php/ arcosdesign]

\section{DOI}

10.12957/arcosdesign.2013.10004

\section{(c) (i) (2) (2)}

A Revista Arcos Design está licenciada sob uma licença Creative Commons Atribuição - Não Comercial - Compartilha Igual 3.0 Não Adaptada. 